\title{
Parietal foramina with clavicular hypoplasia
}

INSERM

\section{Source}

INSERM. (1999). Orphanet: an online rare disease and orphan drug data base. Parietal foramina with clavicular hypoplasia. ORPHA:251290

Parietal foramina with clavicular hypoplasia is a rare genetic bone development disorder characterized by parietal foramina in association with hypoplasia of the clavicles (short abnormal clavicles with tapering lateral ends, with or without loss of the acromion). Additional features may include mild craniofacial dysmorphism (macrocephaly, broad forehead and frontal bossing). No dental abnormalities were reported. 